\title{
Midiatização: dispositivos, processos sociais e de comunicação ${ }^{1}$
}

\author{
Jairo Ferreira ${ }^{2}$
}

\begin{abstract}
Resumo: Neste artigo, desenvolvemos proposições teóricas em relação ao conceito de midiatização, em três momentos. Primeiro, apresentamos o modelo geral: a midiatização como relações $e$ intersecções entre dispositivo midiáticos (Ferreira, 2006), 'processos sociais' e de 'processos de comunicação'. Segundo, apresentamos os cenários de reflexão sobre o tema. Terceiro, sugerimos o conceito de dispositivos como foco da proposição teórica que desenvolvemos. Nas relações entre dispositivos, processos sociais e processos de comunicação, entendemos que o conceito de adaptação permite superar as (falsas) antinomias entre "experiência midiatizada" e "experiência mediada" (Matta).
\end{abstract}

Palavras-chave: midiatização, processos sociais e processos de comunicação.

\section{Introdução: hipótese geral ${ }^{3}$}

O conceito de midiatização que desenvolvemos está articulado a partir de três pólos em relação de mútua determinação, formando uma matriz de midiatização. Nessa matriz primária, não só cada um dos pólos condiciona o outro, como cada um pode interceder nas relações entre os dois. Nesse sentido, as relações possíveis para o estudo da midiatização podem também ser pensadas graficamente como já havíamos feito com o conceito de

Agradeço em particular as considerações críticas de Maria Immacolata Vassalo Lopes (o último encontro da Compós. Lopes, 2007b).Suas críticas estão divididas em duas partes. A primeira foi tratada em artigo publicado no Livro Cenários, Teorias e Epistemologias da Comunicação (E-Papers), organizado por mim. A segunda parte do relato da professora Immacolata coloca duas questões que retomo aqui: o lugar da tecnologia na comunicação e a relação da midiatização com as mediações sociais. Esse segundo aspecto, está, aqui ainda insuficiente, mas retrato ele de forma ampla. Meus sinceros agradecimentos a professora Immacolata.

Prof. Dr. e Pesquisador da Unisinos ( jferreira@unisinos.br).

3 Essas reflexões se desenvolvem como fundamentação teórica da pesquisa sobre a circulação midiática, intitulada "A circulação em dispositivos midiáticos (estudo sobre as ONGs em sites na Web)”. Apoio: CNPq, Fapergs, Unisinos. E-mail]: jferreira@ unisinos.br. Bolsistas de IC: Eduardo Araújo (UNIBIC) e Carine Ferreira (PIBIC) e André Carvalho (Fapergs). 
dispositivos (Ferreira, 2006). O foco desse artigo é definir a midiatização a partir dessas relações e intersecções entre dispositivos (DISP), processos sociais (PS) e processos de comunicação (PC):

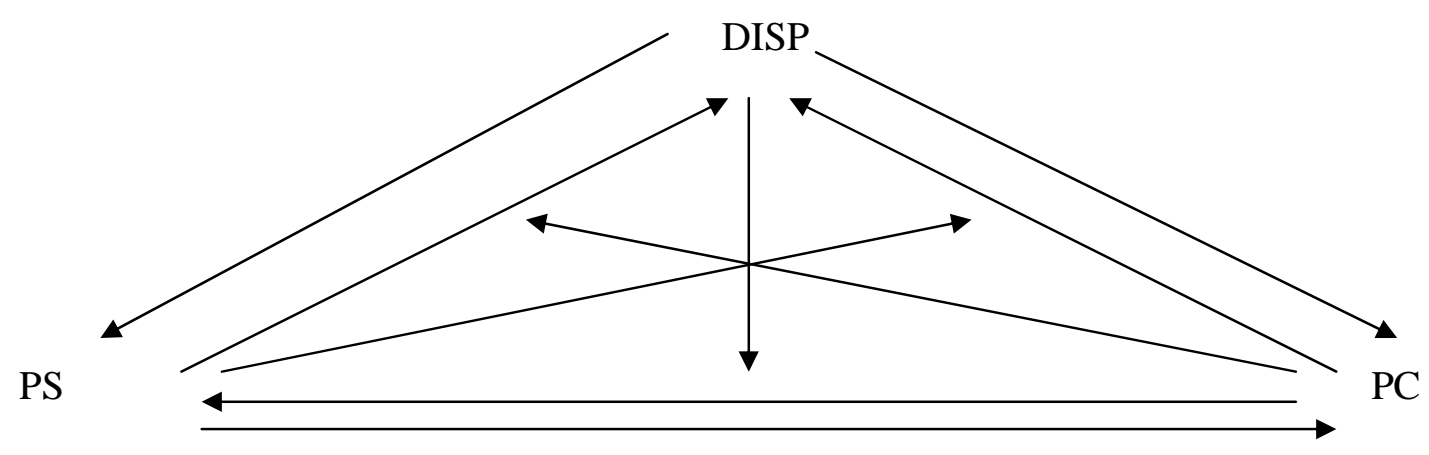

Essa matriz primária indica um conjunto de relações possíveis de interpretação da midiatização. É um conjunto teórico e, portanto, abstrato. Sendo a análise relacional com os processos sociais e de comunicação em jogo, somente por uma abstração é possível separar as três dimensões, que devem, num segundo movimento de análise, ser reintegradas para que possamos falar de midiatização. Esse movimento de abstração pura para a construção do conceito, em geral, deve ser sempre superado para a compreensão de processos de comunicação e processos sociais com os quais se relacionam as "mídias”. Nesse sentido, é necessário, depois de uma realização uma abstração “exagerada” de interpretação, retomar outros eixos de abstração que possamos identificar como produtivos para pensar a comunicação. Esse é o método histórico-dialético que procuramos manter em nossas elaborações (abstrações e concretizações como relações entre várias categorias abstratas).

Em termos mais concretos, as relações desenhadas informam que os dispositivos são configurados conforme determinados processos sociais (analisados pela sociologia, antropologia, psicologia social, ciência política, economia, etc.), mas também são por eles configurados; que os dispositivos afetam os processos de comunicação, assim como são delineados por esses; e que os processos de comunicação e a produção social estão em 
relação, inclusive no que se refere às práticas sociais estruturadas e às distribuições das condições de existência individuais e institucionais. As intersecções se referem aos processos em que um determinado pólo atua sobre as relações dos outros dois. Assim, os processos de comunicação intercedem sobre as relações entre os dispositivos e processos sociais; os dispositivos sobre as relações entre os processos sociais e a comunicação; etc. Cada um desses processos intercede nos outros (assim, as relações entre processos sociais e processos de comunicação são, cada vez mais, interseccionadas pelos processos acionados sobre os dispositivos midiáticos, etc). O diagrama informa ainda que, em cada vértice, há conhecimentos nucleares para pensar a midiatização conforme nossa proposição.

\section{Cenário de reflexão sobre a midiatização}

A compreensão da midiatização a partir dessas relações decorre de discussões já desenvolvidas no campo acadêmico da comunicação. Assim, os processos sociais aparecem no debate do campo acadêmico da comunicação em relação com perspectivas que requisitam as contribuições de teorias sociais de diversas origens (sociologia, a psicologia, a antropologia, filosofia, as teorias do signo, etc.). Aqui, o comunicólogo deve, necessariamente, entrar em contato com conhecimentos que estão sendo produzidos em outros campos acadêmicos, quem nem sempre tem como ponto de partida o problema comunicacional ou midiático. Os conceitos de indivíduo, sujeito, ator, agente, sociedade, instituição, interações, mercados, valores, condutas, subjetividade, cognição, inconsciente, consciência, ideologia, estrutura, linguagem, etc. são oriundos dessas reflexões.

Essas formulações são condições de interpretação que permitem superar leituras ingênuas sobre os processos sociais. A ausência em geral leva a reflexão a pontos e 
equações já visitadas pelas ciências sociais, pelas teorias do signo e pela filosofia. A apropriação dessas formulações requer um trabalho específico, de superação das mesmas pela via do foco em problemas de comunicação e das “mídias”. A difícil e tortuosa processualidade de incorporação desses conhecimentos a problemas específicos do campo epistemológico da comunicação, e o desafio da construção de uma identidade própria, não tem impedido um retorno permanente às fontes filosóficas, sociológicas, antropológicas, etc. que permite atualizar e coordenar o conhecimento da área relativamente às ciências sociais, e da linguagem em geral.

A dificuldade maior relativamente a esse movimento teórico é que a ida às fontes resulta, muitas vezes, em aprisionamento aos problemas típicos produzidos em outros campos e disciplinas acadêmicas, onde dezenas, centenas e, às vezes, milhares de investigadores se dedicam aos sofisticados debates de diferenciação dos conhecimentos relativos aos objetos por eles constituídos.

Essas perspectivas são particularmente importantes quando abordam as relações dos processos sociais, processos de comunicação e “mídia”. Em geral, essas relações são analisadas com a propensão de subordinar os processos de comunicação às categorias sociais construídas pelas ciências sociais e da linguagem. Assim, a comunicação e a “mídia” são entendidas como subordinadas ao problema da distinção, das classes, dos capitais, da construção dos sujeitos, dos atores, de suas condições de existência, etc. Essa subordinação aos processos sociais é, sem dúvida, produtiva no sentido de ultrapassar 'utopias ideológicas', inclusive porque a reflexão teórica e conceitual sobre essas incidências permite ver como os processos sociais capturam as relações de comunicação.

Essas perspectivas decorrem de que a superação de lugares de senso comum solicita, portanto, conhecimento das ciências sociais, teorias do signo e filosofia, que, inclusive, também estão na origem do debate sobre a especificidade da comunicação, enquanto processo de constituição de novos sentidos da vida. A comunicação enquanto processo de 
interação conversacional, verbal e não-verbal, de atos de linguagem, de compartilhamentos, de construção de sentido através dos agenciamentos signicos, de elucidação, discernimento, coordenação de ações, crítica social, comunhão, etc. são conceitos produzidos em diversas disciplinas e campos acadêmicos das ciências sociais e do signo, e não só do campo acadêmico da comunicação. Aqui há um jogo de reflexões, objetos conceituais e teóricos em disputa, na medida em que o campo acadêmico e epistemológico da comunicação procura demarcar sua identidade, o que, entretanto, não invalide a constante apropriação, pela própria área, de conhecimentos sobre o comunicacional produzidos em outros campos e disciplinas. O debate sai, aqui, de um lugar subordinado, para uma posição mais confortável, na medida em que tais jogos teóricos e conceituais, estão, em boa medida, alimentados por processos de análise não só teóricos e formais, mas também dedutivos, indutivos, colocando a área em condições a "legitimidade” na produção do conhecimento sobre o comunicacional.

Nesse sentido, importante são os processos em as ciências sociais, da linguagem e filosofia se “dobram” à análise de novos processos sociais relacionados às “mídias”, produzindo, no seu interior, uma atualização conceitual em relação às suas próprias origens. O conceito de príncipe eletrônico (Ianni, 2001), de idade das mídias (Poster, 1990), a configuração de uma teoria midiática (Lasch, 2005), etc. são esforços que reforçam o deslocamento teórico e epistemológico de outros campos e disciplinas para a análise das "mídias", que inclusive superam formulações mais impregnados pelo debate da cultura, economia e política (tais como o de indústria cultural, economia política da comunicação, cultura das mídias, etc.).

A apropriação desses conhecimentos pelo campo acadêmico da comunicação se faz também em nova correlação de forças entre campos acadêmicos. O campo acadêmico da comunicação assume, nesse terreno, um lugar próprio, de reconhecimento diferenciado em termos de vantagens no mercado acadêmico. Aqui, o fato de que tais apropriações sejam produzidas no âmbito de pesquisas experimentais sobre as "mídias” alimenta um processo 
de vantagens comparativas, cada vez maiores, relativamente às teorias sociais, da linguagem e filosofia de produzidas em outros campos acadêmicos e disciplinas. Nessas correlações, particularmente importantes no campo acadêmico da comunicação são os estudos de caráter empírico-experimental, conceitos e teorias que abordam as relações das “mídias” com a comunicação, diferenciada, agora, em produção, consumo, circulação, como lugares específicos de produção de novos processos sociais, ao mesmo tempo em que intersecionados por esses.

Nosso entendimento é de que o conjunto dessas formulações sobre as relações entre processos sociais, de comunicação e a “mídia”, parte de naturalizações dos nomes “meios”, “mídias”, quando não de termos mais vagos ainda (aparatos, suportes, etc.). Nesse sentido, o esforço teórico sobre a midiatização requisita, um conjunto conceitual próprio do campo acadêmico da comunicação sobre o que é termo de origem do conceito de midiatização (ou seja, algo em ação através das “mídias”). O foco que estamos desenvolvendo é o de dispositivos (Ferreira, 2006), sem querer, com ele esgotar outras dimensões em debate (meios, suportes e mídia, inclusive), mas remetendo a elas.

\section{Dispositivos, processos sociais e de comunicação}

O conceito de dispositivos é produzido nas ciências sociais (Foucault), e, simultaneamente, nasce a partir de reflexões específicas do campo da comunicação (análise da imagem, cinema e televisão). Ou seja, talvez seja o caso singular de um conceito e reflexão teórica que demarca uma convergência histórica, em que os processos sociais, processos de comunicação e "a mídia” estejam em inter-relações (Poster, 1990, Fidalgo, 2006). Simultaneamente, o conceito remete a uma singularidade que coloca em jogo 
relações entre sociedade, tecnologia e linguagem incorporados e materializados (Ferreira, 2006), como pode ser observadores em autores como Aumont (1995, análise da imagem), Dubois (s/d, cinema), Carlon (1995, telejornais), Mouillaud (1997, jornal impresso). Afirmamos, assim, que o dispositivo é, por um lado, um conjunto de materialidades (passíveis de uma análise triádica, como temos sugerido), e, por outro, o conjunto de relações e intersecções com processos sociais e de comunicação.

Pode-se questionar o nome (dispositivo de comunicação e midiáticos). Chamamos assim em decorrência de uma especificidade. O conceito de dispositivos é muito genérico. É válido para todos e quaisquer dispositivos, embora avaliemos que o conceito remeta sempre a uma processualidade da comunicação (agenciamentos entre o ver e o dizer). Mas o conceito permite-se num lugar genérico para as ciências sociais. É considerado válido para análise de outras experiências sociais, que não a midiática e comunicacional (o conceito aparece na educação, na sociologia do trabalho, etc.). Isso requer, em nossa interpretação, a necessidade de diferenciá-lo para pensarmos a comunicação. Essa diferenciação começa pelo “nome”.

Para compreender a midiatização, o conceito deve focar os dispositivos midiáticos, sendo o segundo termo desnecessário quando se trata de compreender os processos de comunicação. Somente nos dispositivos midiáticos, se explicita, com toda a força, as dimensões constitutivas específicas da midiatização, embora não sejam apenas “eles” que configurem o que é, por diferenciação histórica e social, os processos de midiatização. Assim, muitos dispositivos de comunicação em geral são integrados aos processos de midiatização, o que se expressa em categorias específicas dos dispositivos midiáticos - as dimensões técnicas, tecnológicas e discursivas, mais diferenciadas do que em dispositivos em geral, no que se refere às dimensões constitutivas. O dispositivo midiático atualiza os agenciamentos do visível e do dizível, do antropológico, das técnicas e das tecnologias. 
Em suas materialidades, propomos que a análise do dispositivo midiático se configure a partir de uma matriz primária triádica ${ }^{4}$. Afirmamos que é compreensível o dispositivo a partir das múltiplas articulações entre as três esferas de operam simultaneamente sobre as outras dimensões, desde os momentos que cada uma das dimensões se configura como sistema (portanto, operações próprias, autônomas em relação às outras). Essa operação sobre a outra, em que a outra se transforma em matéria prima de suas operações, é que permite pensar o dispositivo como matrizes abissais ${ }^{5}$, e não como linha ou plano. Por isso, o dispositivo midiático não é um sistema, mas conjunto de sistemas em co-operações, muitas das quais deslizantes entre si, na medida em que nem sempre ocorrem acoplamentos mas sim justaposições ações.

As três dimensões do dispositivo midiático são três grandes agrupamentos que observamos recorrentes nas análises realizadas nas ciências sociais, e no campo acadêmico da comunicação, em particular quando fazem referência explícita ao conceito de dispositivos. O desafio teórico permanente é que análise dos dispositivos passa pela identificação das operações em jogo, discernindo-as, e, posteriormente, colocando-as em relações e intersecções. Considerando-se o “estado da arte” do campo acadêmico da comunicação, não há, aqui, porque "reinventar a roda”. A literatura disponível é farta em oferecer análise das operações técno-tecnológicas, semio-lingüística-discursiva e sócioantropológicas na análise dos dispositivos, fazendo ou não referência explicita a esse conceito. Essas análises, em geral, se concentram nos sistemas em jogo nos dispositivos, e, por isso mesmo, consideramos que não são análises dos dispositivos. Analisar o dispositivo

4 A proposição de que o dispositivo é triádico - um sistema social, tecnologia e linguagem - foi feita por Peraya (1999), mas aparece também em Levy (1997). Desenvolvemos essa proposição enquanto abordagem triádica dos dispositivos em Ferreira (2006).

5 As matrizes são abissais na medida em que são infinitas as possibilidades combinatórias fundadas pela matriz primária. O esforço analítico é simplesmente uma abstração, com pretensões de retorno às totalidades (o concreto pensado de Marx) interpretativas. Retorno, esse, nunca realizado, ou realizável. O sonho autoritário do marxismo, do leninismo, foi sempre querer dar conta desse retorno, desejado, mas sempre fluído, que escorrega pelas entranhas do pensamento. E das ações. 
requer um esforço específico: colocar as relações e intersecções entre várias operações (e, portanto, co-operações). Voltaremos a esse tópico.

A análise do dispositivo em sua materialidade, em especial se compreendido com uma constelação de operações de diversos níveis e naturezas, deve se enfrentar, num segundo momento, com suas relações com os processos sociais e processos de comunicação. As perspectivas unidirecionais acentuam como esses processos sociais ou processos de comunicação são regulados a partir dos dispositivos, ou, inversamente, de como, em última instância, os dispositivos são envolvidos, concernidos, apropriados, etc. conforme os processos sociais e de comunicação. Essas duas perspectiva unidirecionais enfrentam-se, permanentemente, nos embates epistemológicos, teóricos e metodológicos no campo acadêmico da comunicação. Para além de uma antinomia desenhada por unidirecionalidades de condicionamentos e concernimentos, sugerimos explorar as perspectivas interacionistas, que, em relação com a perspectiva epistemológica e analítica sistêmica, permite recuperar, nas análises das inter-relações dos dispositivos com os processos de comunicação e sociais, as boas heranças do estruturalismo genético ou construtivista de Marx a Bourdieu, passando Piaget, entre outros.

As análises que remetem as relações e intersecções é que propiciam a inteligibilidade do lugar do dispositivo na midiatização da sociedade. Inversamente, portanto, permitem compreender o dispositivo em termos amplos - o universo social -, onde as materialidades específicas estão em permanente reconstrução. 


\section{Indisposições e adaptações}

A materialização dos dispositivos sociais em geral em dispositivos midiáticos transcorre pelo que chamamos de cobertura de ciclos funcional, simbólico e cognitivo das ações sociais em geral, e comunicativa, em específico, às materialidades resultantes das diversas operações que agrupamos como sócio-antropológicas, semio-discursivas, e técnicas e tecnológicas. Em geral, esses processos de cíclicos podem ser identificados na literatura sobre dispositivos (mesmo quando não fundamentadas na perspectiva triádica que desenvolvemos). Exemplo do ciclo funcional é a análise que Dubois (s/d) faz da substituição da ação humana pela máquina nos processos de silhuetar; de ciclo simbólico, é a substituição do trabalho psíquico pela máquina de imaginários do cinema (na medida em que condensa tempos e espaços diferidos na seqüencialidade resultante da montagem), como analisa Baudry (2003); de ciclo cognitivo, pelos processos de indexalidade das informações, conforme pode ser visto em Mouillaud (1997); do ciclo das operações signicas, em que novos relações entre índice, ícone e símbolo são produzidas conforme os dispositivos (Veron, 2001). Etc.

Estou convencido de que é esse conjunto de operações cíclicas de cobertura, incorporação, objetivação que resultam, também, em subsunção em parte dos processos sociais de comunicação e sociais de produção de sentido - constitui-se no ponto de partida dos contratos vinculares dos indivíduos com os dispositivos midiáticos em suas várias formatações. São novas formas da permanente transformação do trabalho vivo em trabalho morto (Marx), que produzem desequilíbrios na esfera da produção, consumo e circulação midiáticos, e na produção social de sentido. A relação aqui, entretanto, não é unidirecional. Os processos sociais e de comunicação incidem sobre as materializações, e, de forma circular, retroagem sobre os processos sociais e processos de comunicação anteriores, requisitando novos esquemas de subjetividade, de ação e acomodação histórica e social. 
Nesse sentido, compreendemos que para entender a midiatização, é necessário superar as várias ideologias em jogo na análise do conceito. É ideológica a propensão a subordinar o processo de midiatização às estratégias dos processos sociais em jogo (sejam, os econômicos, os políticos ou os culturais), mas também o inverso (subordinar o mundo da vida, e os mercados, completamente, aos sentidos em jogo nos vínculos com os dispositivos midiáticos). O mesmo pode se dizer das relações entre os dispositivos e os processos de comunicação.

Nesse conjunto, uma ideologia particular, no campo acadêmico da comunicação, é a subordinação dessas relações e intersecções a técnica e a tecnologia, consideradas como centro dos processos de midiatização. Essa ideologia se fortalece inclusive em decorrência das representações de parte considerável dos comunicadores contemporâneos que operam nas instituições midiáticas, que estabelecem uma relação de identidade e performance tecnológica, e da tecnologia enquanto ideologia (questão vista por Marcuse e Habermas, mas se referindo à teoria social em geral, e não especificamente aos processos de midiatização).

Pensar para além dos limites da tecnologia como ideologia, é necessário compreender, na construção do conceito de midiatização, que essa é produzida, induzida(s) e regulada pelo conjunto das relações e intersecções entre processos sociais e processos de comunicação, incidindo sobre as materialidades dos dispositivos midiáticos em seu conjunto (espaço, tempo, agenciamentos signicos, técnica e tecnologia), e não apenas em uma de suas dimensões.

Refletir sobre esse conjunto de relações e intersecções de forma não unidirecional requisita a retomada do conceito de adaptação (Piaget, Habermas), em que as relações entre dispositivos midiáticos, processos sociais e processos de comunicação, não se reduzem nem “a experiência mediada”, nem à “experiência midiatizada”, mas compõem uma dialética adaptativa entre processos de objetivação e subjetivação, no caso relacionados 
especificamente às materialidades (objetivações sociais) dos dispositivos midiáticos. Essa perspectiva de análise adaptativa corresponde à abordagem sistêmico-interacionista.

\section{Referências bibliográficas}

AUMONT, Jacques. A parte do dispositivo. In: A imagem. 2. ed. Campinas: Papirus, 1995. p. 135 - 195

BAUDRY, Jean-Louis. Cinema: efeitos ideológicos produzidos pelo aparelho de base. In: XAVIER, Ismail. A experiência do cinema. 2003. São Paulo: 2003.

BELIN, Emmanuel. De la bienveillance dispositive. In: Le Dispositif - Entre usage et concept. Hermes 25: Cognition, Communication, Politique. Paris: CNRS Éditions, 1999. p. $245-259$.

BRAGA, José Luiz. Sobre "mediatização" como processo interacional de referência. GT Comunicação e Sociabilidade, 15 Encontro Anual da Compós, Bauru: junho de 2006. Cd-rom.

CARLON, Mario. Sobre lo televisivo. Dispositivos, discursos y sujetos. Tucuman: La Crujia, 1999.

DELEUZE, Gilles. Foucault. Rio de Janeiro: Brasiliense, 2005.

DUBOIS, Philippe. Máquinas de imagens: uma questão de linha geral. In: Cinema, vídeo. Godard. São Paulo: COSACNAIFY, [S.d.]. p. 31 - 67.

FERREIRA, Jairo (org). Cenários, teorias e epistemologias da comunicação. Rio de Janeiro, E-papers, 2007.

FERREIRA, Jairo. Uma abordagem triádica dos dispositivos midiáticos. Líbero (FACASPER), v. 1, p. 1-15, 2006. 
FIDALGO, Antonio. O modo de informação de Mark Poster. Disponível em: $<$ http://www.bocc.ubi.pt/pag/fidalgo-antonio-poster-modo-informacao.pdf $>$ Data de acesso: jul/2006.

IANNI, Octávio. O príncipe eletrônico. In: Enigmas da modernidade. Rio de Janeiro: Civilização Brasileira, 2001. p. 141-166.

LASCH, Scott. Crítica de la información. Buenos Aires: Amorrortu, 2005. p. 39-58, p. 119-138.

LEVY, Pierre (1997). Cyberculture. Paris: Odile Jacob.

LOPES, Maria Immacolata Vassalo de. Comunicação, disciplinaridade e pensamento complexo. In: GT de Epistemologia da Comunicação. XVI COMPÓS: Curitiba/PR, 2007.

LOPES, Maria Immacolata Vassalo de. Relato ao texto "Algumas linhagens de construção do campo epistemológico da comunicação". In: GT de Epistemologia da Comunicação. Compos, 2007, CuritibaCuritiba/PR, 2007b.

MATA, Maria Cristina. De la cultura massiva a la cultura midiática. Diálogos de la comunicación. Lima: FELAFACS, s/d. p. 80-91.

MOUILLAUD, Maurice e PORTO, Sergio Dayrell. O Jornal: da forma ao sentido. Brasília: Paralelo, 1997.

PERAYA, Daniel. Médiation et médiatisation : le campus virtuel. ?. In: Le Dispositif Entre usage et concept. Hermes 25: Cognition, Communication, Politique. Paris.

VERÓN, Eliseo. Esquema para el análisis de la mediatización. Diálogos de la comunicación. N.48. Lima: Felafacs, 1997. p. 9-17.

VERON, Eliseu. Los públicos entre producción y recepción: problemas para una teoría del reconocimiento. Curso da Arrábida: Público, Televisão. 2001.18 p.

POSTER, Mark. The mode of information. Poststructuralism and Social Context. Chicago: University of Chicago Press, 1990. 